\section{Development of A Design Thinking- Based Korean Language Curriculum Literacy Program for Preliminary Korean Language Teachers}

\author{
Jinhee Kim \\ Department of Korean Language Education, Kyungnam University, Changwon, Korea
}

Purpose: To demonstrate that curriculum expertise required of prospective Korean teachers based on design thinking is needed for both the development and implementation of programs relevant to student needs.

Methods: The concepts and characteristics of design thinking, followed by its relevance to teacher education were explored. Then concepts and elements within the theory informing curriculum literacy were reviewed before articulating its value in professional development of Korean language teachers' curriculum literacy.

Results: Based on theoretical considerations, a program that can enhance Korean language curriculum literacy according to the stages of design thinking was developed.

Conclusion: The results of this study suggest that preliminary Korean language teachers will be able to systematically develop the curriculum expertise required of teachers by participating in the Korean language curriculum literacy program of teacher training institutes.

Keywords: Design Thinking; Korean Language Curriculum Literacy; Preliminary Korean Language Teachers

\section{INTRODUCTION}

Contemporary educational methodologies and philosophies like Problem-based Learning (PBL) that aim for more student-centred processes for learning, require teachers to assist learners to come to meaningful learning through a thorough examination of the processes used to arrive at their understandings. In this paper, the professional practice examined is that of teacher education, specifically focussing on the concept of curriculum literacy. i.e., the ability to develop, implement and evaluate curricula. The specific real-world context of the person responsible for this professional development is developing curriculum literacy in Korean language teachers.

Although national-level curricula present educational goals, content, and methods and the direction of evaluation, there are clear differences from the classroom-level implementation where various and complex elements dynamic classroom instructions are intertwined. Therefore, no matter how well national-level curricula outline the changes of the times and society, the success or failure of education is determined by how the curricula are implemented in practical situations at the school or classroom level.

The 2015 revised curriculum recently announced by the Ministry of Education aims to cultivate talented individuals equipped with creative convergent thinking and problem-solving capabilities. Therefore, teachers must have the professional competence to actively develop, practice, and evaluate curricula in the practical educative situations, rather than passively imple-
pISSN 2288-8675 · elSSN 2508-9145

J Probl Based Learn 2022;9(1):46-55 https://doi.org/10.24313/jpbl.2021.00087

Received: October 1, 2021

Revised: January 25, 2022

Accepted: February 08, 2022

Corresponding author:

Jinhee Kim

Department of Korean Language

Education, Kyungnam University, 7

Kyungnamdaehak-ro, Masanhappo-

gu, Chongwon-si, 51767 Korea

Tel: +82-10-7335-7221

Fax: +82-54-246-7221

E-mail: koreanedu@kyungnam.ac.kr
(C) 2022 International Society for Problem-Based Learning

(c) This is an Open Access article distributed under the terms of the Creative Commons Attribution Non-Commercial License (http://creativecommons.org/licenses/ by-nc/4.0/) which permits unrestricted non-commercial use, distribution, and reproduction in any medium, provided the original work is properly cited. 
menting the national-level curriculum.

As autonomous operators of the curricula, teachers are required to have the ability to interpret and autonomously come to an understanding of national curricula, develop them into appropriate classroom-level programs considering context variables (students, classrooms, schools, local communities, educational policies, etc.) and implement the resultant curriculum as learning events. This ability is referred to as curriculum literacy.

Although curriculum literacy is a very important professional and core competency required of teachers, there are few high-quality studies on developing curriculum literacy and discussions on the development of professional attributes within teacher education programs. Given the reality that teachers who teach subjects in secondary schools often take a one-time training course to develop curriculum literacy for reasons of entrance exam guidance and workload, it is believed that systematic education for the development of preliminary teachers' educational curriculum literacy is necessary at colleges of education that cultivate secondary school teachers. Therefore, based on the definition of curriculum literacy required of teachers, the present study proposes an educational program that can contribute to the development of the Korean language curriculum literacy of preliminary Korean language teachers who are preparing to become secondary school Korean language teachers.

Korean language curriculum literacy points towards the curriculum expertise required of Korean language teachers and is limited to the subject of Korean language from the concept of curriculum literacy. In particular, the present study tried to develop a design thinking-based education program to successfully support curriculum literacy development education for preliminary Korean language teachers. Design thinking is also an educational methodology developed by IDEO and Stanford University based on the thinking style of designers who innovate and create objects. Design thinking is regarded as a creative problem-solving strategy necessary for solving real-world problems and is widely used in fields such as design, management, society, and education.

There is little interest in design thinking in teacher education, and it has hardly been discussed in relation to the Korean language subject. Studies related to curriculum expertise include Park (2019), but these are not empirical studies on design thinking education.

In classrooms, teachers undertake tasks to creatively solve classroom management problems in which complex elements such as the level and demands of students, textbooks, media, and classroom space as well as addressing specific elements of national-level curricula are entangled. Therefore, teachers are curriculum designers who must also develop and implement classroom-level curricula.

It is important to acknowledge that the content of Korean language education includes the knowledge, skills, and attitudes necessary for actual human linguistic practice, and a characteristic of Korean language education is dealing with language phenomena, which are problems that are diversified and complex, and cannot be solved entirely. In addition, the essence of language includes communication, cognitive, and problem-solving processes. Design thinking also includes a process of cooperatively solving problems through communication and cognitive processes.

Considering the various aspects outlined above, design thinking has the potential to be applied to Korean language development and curriculum literacy for teacher education. Therefore, the present study aims to develop a design thinking-based educational program that focuses on improving the curriculum literacy of preliminary Korean language teachers. This program can be used by colleges of education that train secondary school Korean language teachers.

\section{METHODS}

\section{Concept and characteristics of design thinking}

Design thinking discourse around the way designers engage in processes of work performance began in the 1960s; discussion about this approach continued until the 1990s. The term was first used by cognitive psychologist Herbert Simon in "The Sciences of the Artificial" (1969). He defined design thinking as "a process to solve all problems in human life, such as society, culture, economy, politics, and environments through interdisciplinary cooperation in mesh with the integrative and comprehensive problem-solving ability of design" (Kim 2015). Since the 2000s, discussion has turned to the concept as an innovation strategy in the management discourse of companies or organizations. Tim Brown of IDEO, a design consulting firm, said in the feature article "IDEO Design Thinking" in the Harvard Business Review in 2008, that design thinking is necessary to solve complex problems.

The momentum for design thinking to appear in educational discourse was the establishment of Stanford University's d.school. This school established a series of thinking processes that went beyond the conceptual level and implemented 'design thinking education. This has resulted in a new educational methodology that can foster creative problem-solving ability. D-School's design thinking process consists of five stages.

Empathize, the first stage, is where one observes people facing a problem and forms a consensus with them. To that end, one uses methods such as field surveys, follow-up observations, interviews, and questionnaire surveys. In the second stage, Define, the prob- 
lem that must be solved is identified based on the results obtained in the Empathize stage. In the third stage, Ideate, one collects various ideas to solve the defined problem. Examination of the problem from various angles occurs, using methods such as brainstorming, and brainwriting based on intuition, experience, and expression of opinion with an open attitude and permissive atmosphere to welcome any idea. In the fourth stage, Prototype, these are quickly developed based on the derived ideas with cheap materials, checking the feasibility of the ideas through immediate feedback. In the final fifth stage, Test, the prototypes are applied to actual situations to evaluate whether the ideas are suitable for solving the problem.

The characteristics of design thinking that progresses in five stages can be summarized as follows. First, design thinking is an innovative thinking methodology that provides human-centered solutions to problems. Design thinking regards activities such as observing, emphasizing with, and analyzing human problem situations as important to solve problems. Second, design thinking acknowledges collective intelligence and cooperative problem-solving processes as important. To solve problems in which complex elements are intertwined, people with various ideas, experiences, and abilities gather and enjoy the process of finding solutions through various experiments. Third, design thinking seeks a balance between convergent and divergent thinking. The five-step thinking process involves repetition of the processes of divergence and convergence.

\section{Design thinking and teacher education}

Recently, design thinking has been seen as a key to solving the problems of future-oriented education. Accordingly, interest is growing in the concept as a core element for quality teacher professionalism. However, discussion on design thinking in teacher education seems limited; discussion can be divided into conceptualization of design thinking, its educational effects, and teachers' perceptions of it.

First, studies that conceptualized design thinking in terms of teacher education are examined. Kim et al. (2014) cited the fact that as a future educational paradigm, design thinking in the field of pedagogy aims to make learners constructively create new values and knowledge and aim for desirable changes in the learning group. They suggest that it is focused on solving difficult problems in education and that it promotes collaboration and participation. It is also suggested that it pursues visualization, and that it is focused on problem solving and processes as conceptual characteristics.

Kim et al. (2018) make the point that educational design is accepted as a universal learning approach involving classroom lectures and curriculum frameworks. Educational activities combine design thinking, school space design, and universal design. Design is used as a strategic method to overcome the problems of education and promote changes in education in the future. The above two studies highlight the attributes of design and provide a clue about how future approaches to education should respond to the impact of social challenges. Unlike the above studies, Park (2019) said that design thinking makes preliminary teachers form a habit to better understand and solve problems in a manner that designers do. In this way preservice classes enable prospective teachers to become more flexible and adaptive teachers. Park's study (2019) viewed teachers as designers and suggested that design thinking is necessary to foster the professionalism of teachers.

Second, there are studies that applied design thinking to teacher education and verified the educational effectiveness using quantitative research methods. Nam et al. (2019) indicated that there were significant differences in learners' group cohesiveness (group task-related integration) and cooperative learning attitudes (reward interdependence). Park (2017) developed a design thinking-based class design model, and in a follow-up study, Park (2019) reported that the educational effects were verified and helped preliminary secondary teachers in their class design ability.

Third, there are qualitative studies on teachers' perceptions of design thinking. Lee \& Ahn, (2020) reported that classes using a design thinking model were conducted for young children, and according to the results, the classes had significant effects in terms of creativity, empathy ability, flexible thinking, considerate thinking, and enjoyment of collaboration. Lee \& Kim, (2020) analyzed design thinking-based educational practice activities and found that active participation increased over time, and participants emphasized the necessity of design thinking.

To judge from the study results above, design thinking is an educational methodology that can contribute to solving complex problems inherent in educational phenomena and is an educational device that is expected to have positive educational effects.

A useful example of the interrogation of the thinking processes in a professional practice is that presented by Razzouk \& Shute, (2012) in relation to the professional practice of Design. They present a set of dimensions, which they argue describes the differences among disciplines/professional practice and their ways of thinking and proposes a process of thinking that describes and informs the professional practice of design. At the same time, they argue that other professions would use different processes based on the placings along each of the four dimensions and that the position of the discipline/profession may vary in different circumstances and therefore apply multiple ways of thinking in any given situation. The dimensions are on 2 axes: the horizontal describes the processes - finders or discoverers (analytical) and the makers 
(synthesisers): the vertical axis describes the content, being symbolic (representation) and real (real world). The two axes result in 4 quadrants: Analytical Symbolic. Synthetic Symbolic; Analytic Real; Synthetic Real. The authors argue that Designers are mostly Synthetic Real.

In this paper, the professional practice examined is that of education, specifically, curriculum literacy. i.e., the ability to develop, implement and evaluate curricula. The specific real-world context is developing curriculum literacy in Korean language teachers. It can be argued that Teacher Educators are in the Synthetic Real quadrant, i.e they are making new meaning for the learner, new ways of thinking about the real world of teaching/and learning and developing creative solutions to classroom teaching such as PBL itself.

\section{Concept and elements of Korean language curriculum lit- eracy}

Literacy refers to "the ability to read and write" and has recently been extended to the ability to interpret, understand, and think critically about something. Earlier the concept of curriculum literacy was defined as the ability of teachers to use, improve, and develop an externally developed curriculum based on their knowledge of the curriculum (Rudduck 1987; Ariav 1988; Ben-Peretz 1990).

Jeong (2002), who first discussed Korean language curriculum literacy, introduced the concept in a study that analyzed the implementation factors and aspects of the Korean language curriculum, and defined it as the ability to read and understand the curriculum and implement it. Studies on the concept are as follows.

Jeong (2012) saw curriculum literacy as necessary for teachers to use national-level curriculum documents and implement them in classes. A study by Paik (2013), which discussed curriculum literacy from a more expanded perspective, regarded it as teachers' ability to comprehensively integrate the background of the curriculum, the basic direction presented, and the content of the subject in their expertise through the learning process to read, interpret, and understand the curriculum and continuously use the outcome in classes. Park et al. (2017) defined curriculum literacy as teachers' ability to go beyond understanding the intention of external developers through the interpretation of the curriculum to the stage where they can rewrite the curriculum, if necessary. Seong (2019) defined curriculum literacy as teachers' ability to interpret various things related to education, develop curricula to fit the field, and implement the curricula.

A study by Song (2020) is a recent noteworthy discussion on teachers' curriculum literacy. This study defined curriculum literacy as the ability of teachers to comprehensively form their knowl- edge of curricula such as the background and basic direction and the content of the subject/s; they could cast their discerning eye for the curricula through a process of reading, interpreting, and understanding curriculum documents and continuously using the knowledge for the development of classroom curricula.

Jeong (2012) and Paik (2013) viewed curriculum literacy from the viewpoint of teachers' "interpretation" or "utilization" of curricula. While Park et al. (2017) and Seong (2019) included viewpoints on "development" and "implementation," Song (2020) emphasized the need for a critical attitude and continuous utilization.

In this regard, the meaning of curriculum literacy is gradually expanding. Referring to the concepts above, Korean language curriculum literacy conceptualized at the level of a certain "subject" refers to the "ability to read, write, develop and implement the Korean language curriculum”. Korean language curriculum literacy is central to the professionalism of teachers who teach Korean language after developing and implementing a classroom-level curriculum based on their interpretation and understanding of the national-level curriculum. The various elements of curriculum literacy that must be developed by teachers are presented by several scholars. Table 1 summarizes previous studies on curriculum elements (Song 2020:36 revision).

In Table 1, curriculum literacy is generally divided into the categories "understanding" and "practice." Curriculum "understanding" is the ability to know and interpret the general theory of curricula, the nature of particulars (subjects), development direction, system, characteristics, goals, contents (achievement standards), teaching and learning methods, evaluation directions, to use curricula. Previous studies included "base, deliberation, analysis, interpretation, reading comprehension" as part of the process of 'understanding'.

Curriculum "practice" involves creating a new curriculum for the purpose of implementing the interpretation of the curriculum in classrooms. To that end, the classroom context, and the curric-

Table 1. Elements of curriculum literacy derived from previous studies

\begin{tabular}{ll}
\hline Scholar & \multicolumn{1}{c}{ Element } \\
\hline Rudduck (1987) & Base, deliberation, adjustment, criticism \\
Ariav (1988) & Analysis \\
Ben-Peretz (1990) & Interpretation, development \\
Jeong (2002) & Meaning, composition \\
Jeong (2012) & Reading, mapping, use \\
Paik (2013) & Reading comprehension, interpretation, utilization \\
Seong (2019) & Interpretation, development \\
Song (2020) & Reading comprehension, use \\
\hline
\end{tabular}


ulum to be implemented are analyzed, interpreted, and organized; class and evaluation plans are established, teaching materials developed, and the classroom environment is created to apply them to actual classes. Previous studies referred to "adjustment, criticism, analysis, composition, mapping, use, utilization, development" as part of 'practice' processes.

From Table 1, the elements of Korean language curriculum literacy can be divided into "understanding" and "practice," and summarized as shown in Table 2.

The concepts and elements of Korean language curriculum literacy presented above were reflected in the development of the design thinking-based Korean language curriculum literacy education program in this study.

\section{Design Thinking-based Korean Language Curriculum Lit- eracy}

Key elements of Program for Preliminary Korean Level Studies

In this study, the direction of development of the design thinking-based Korean language curriculum literacy program was set as follows based on the consideration of previous studies on design thinking-based teacher education, curriculum literacy, Korean language curriculum literacy.

First, the educational goal of this program is to enable preliminary Korean language teachers to cultivate Korean language curriculum literacy using design thinking strategies. The program deals with the knowledge, skills, and attitudes necessary for cultivating Korean language curriculum literacy, focusing on the curriculum expertise that Korean language teachers should have. Keynotes of program composition were derived as shown in Table 3.

Second, in the case of the educational method in this program, the main activity is the thinking process to solve the project topic presented by the researcher. In this program, the preliminary Korean language teachers come together to conduct project activities according to design thinking. The project theme is "Developing a teacher-level Korean language curriculum for Korean language-friendly classrooms and student-customized Korean language classes." In this project, it is assumed that the preliminary Korean language teachers assume the role of "real teachers" and meet a student who is having difficulties in learning the Korean language and develop a customized teacher-level Korean language curriculum together with fellow teachers to explore potential solutions the "student's problem situation."

To that end, the preliminary Korean language teachers must first find the real contributing problematic issues by recruiting, observing, and interviewing students who are experiencing problem situations to carry out the project. Then, the teachers plan an analysis of educational conditions and environments, analysis, results desired from students, curriculum development and operation direction, etc.

Next, the preliminary Korean language teachers analyze the content, system, and achievement standards in the 2015 revised

Table 3. Content of Korean language curriculum literacy program education

\begin{tabular}{ll}
\hline Category & \multicolumn{1}{c}{ Major contents } \\
\hline Knowledge & -Curriculum knowledge \\
& -Korean language curriculum knowledge \\
& -Design thinking knowledge \\
& -Korean language curriculum literacy knowledge \\
Skill & -Design thinking method \\
& -Teacher-level curriculum development method \\
Attitude & - Korean language teachers' attitude as designers \\
& (Developer, Evaluator, Practitioner) \\
\hline
\end{tabular}

Table 2. Elements of curriculum literacy derived from previous studies

\begin{tabular}{ll}
\hline Element & Major content \\
\hline Understanding & - Concept and elements of Korean language curriculum literacy \\
& - Korean language teachers' roles for and attitudes towards the curriculum \\
& - The nature, level, function, system, characteristics, change history of the national-level curriculum (general theory, particulars), \\
& related laws, and guidelines for the national-level curriculum (general theory, particulars) \\
& - Nature, goals, content system, achievement standards, teaching and learning methods and evaluation directions of the Korean \\
& language curriculum \\
& - Exploration of teacher-level curriculum development methods and cases \\
& - Analyzing classroom context (student characteristics, school and classroom environments, teacher philosophy) \\
& - Interpreting and critically understanding the Korean language curriculum \\
Practice & - Organizing teacher-level curriculum (using curriculum template) \\
& - Developing teaching materials and creating a classroom environment \\
& - Implementing the developed teacher-level curriculum \\
& - Getting feedback about the curriculum (students, teachers)
\end{tabular}


Korean language curriculum, and concretely designs integrative teaching/learning and evaluation methods for the Korean language subject areas (listening/speaking, reading, writing, grammar, and literature). In this case, it is also necessary to consider the Korean language materials (discourses, writings, literary works, media texts) and points to note in guidance given the characteristics of the Korean language subject that will be used.

In the development of the integrative curriculum, the principle of integration is important. The central body of the integrated organization is not the acquisition of segmented knowledge within the boundaries of the subject area but is mainly the life of the subject of learning per se, that is, the topics addressed in the subject, social problems or issues, students' problems or matters of interest, topics popular among students, and process-oriented concepts (Beane, 1997; Lee \& Park, 2020). In this study, considering the discourse of design thinking, the "problem situations of students in the classroom," which are the target that must be taught by preliminary Korean language teachers in the field, are set as the main organization for the integration of the curricula that will be developed by the teachers. This reflects the fact that design thinking deals with "complex problems."

Third, although preliminary Korean language teachers undertake training on design thinking and develop Korean language curriculum literacy, they may be still experience difficulty when aspiring to high-quality activities. To create an educational environment suitable for program operation, preliminary Korean language teachers are allowed to freely use various educational materials such as textbooks and teacher guides, and equipment such as computers. In addition, the researcher provides periodic feedback to program participants in the process of carrying out project activities so that the activities do not deviate from project goals.

\section{Object and period of program composition}

The design thinking-based Korean language curriculum literacy program in this study was developed for preliminary Korean language teachers, but it can also be used in classes for incumbent Korean language teachers. Curricula can be developed using various creative problem-solving strategies of design thinking. Whereas the preliminary Korean language teacher may develop the curriculum based on the number of class hours or one textbook unit, the incumbent Korean language teacher may do so based on the semester or grade level. The program can be used to develop not only teacher-level curricula, but also school- or regional-level curricula. The program can be operated for a total of 13 weeks (3 hours per week), as it is most effective and suitable for use in regular classes at teacher training institutions.

\section{Program development}

In this study, to develop preliminary Korean language teachers' design thinking and a Korean language curriculum literacy program, program development stages and activities were derived as shown in Table 4.

Table 4 shows the results of development of the program operation model by reflecting the implications drawn from the above process. The design thinking-based Korean language curriculum literacy program (improved program) for preliminary Korean language teachers developed in this study is explained by the following stages.

First, for class operation, the program was implemented in a lecture room arranged in the form of a classroom where students could perform and discuss tasks face-to-face so that they could break the existing framework of thinking and immerse themselves in creative convergence thinking and task performance activities. Background music was sometimes provided to create a free atmosphere.

In the orientation stage, the content of the program and the study were explained, and class and evaluation methods were introduced. Team building was carried out through various games to enhance student interest and participation.

In the stage aimed at understanding design thinking and Korean language curriculum literacy, the focus was on helping understanding of related content.

In the stage of developing the 'design thinking-based' Korean language curriculum, preliminary Korean language teachers form teams to carry out a project called "Development of a Korean language curriculum for Korean language-friendly classrooms and student-customized Korean language lessons". Here, students who are targeted for customized Korean language classes are "students who have difficulties in learning the Korean language,” who can be easily encountered in school settings. Preliminary Korean language teachers should develop a customized Korean language curriculum to provide Korean language classes for these students.

In the empathizing stage, the teachers carry out in-depth interviews with students experiencing problem situations to find out what problems and difficult situations the students face and empathize with them. After discovering what the problem is, the characteristic of the problem is expressed as a "persona." This is a strategy that analyzes the behavioral pattern of a person experiencing a problem situation to fully appreciate 'who he is, what kind of situation he is in, and what kind of personality he has. After observing and interviewing problem students who are having difficulties in learning the Korean language, the students' personal information, cognitive, affective, behavioral characteristics, and growth process are summarized. 
Table 4. Program composition

\begin{tabular}{|c|c|c|}
\hline Weeks & Stage & Major activities and materials \\
\hline \multirow[t]{3}{*}{$1-2$} & Orientation & Introduction of program purpose and overview \\
\hline & & Team building through various games \\
\hline & & Materials: self-introduction activity sheet, team building activity sheet \\
\hline \multirow[t]{4}{*}{3} & Understanding design thinking, and Korean & View design thinking video \\
\hline & language curriculum literacy & Understanding design thinking \\
\hline & & Experience all stages of design thinking \\
\hline & & Materials: Online class videos, lecture materials \\
\hline \multirow[t]{3}{*}{$4-5$} & & Understanding Korean language curriculum literacy \\
\hline & & Review and mutual discussion of teacher-level Korean language curriculum development cases \\
\hline & & Materials: Online class videos, lecture materials \\
\hline \multirow[t]{5}{*}{$6-7$} & Reality of design thinking-based Korean & [ Empathizing Stage] \\
\hline & language curriculum development & Empathizing interview activities \\
\hline & & Creating a persona for the interview subjects \\
\hline & & Writing reflection journals \\
\hline & & $\begin{array}{l}\text { Materials: [Empathizing Stage] introductory video, expected interview questionnaire, interview log, } \\
\text { persona activity sheet, reflection journal }\end{array}$ \\
\hline \multirow[t]{5}{*}{$8-9$} & & [Problem defining stage] \\
\hline & & 5WHYS (Ohno. 1988), How Might We (Min Basadur 1995) activities \\
\hline & & Problem defining \\
\hline & & Writing reflection journals \\
\hline & & $\begin{array}{l}\text { Materials: [Problem defining stage] introductory video, } 5 \text { WHYS activity sheet, How Might We? ac- } \\
\text { tivity journal, reflection journal }\end{array}$ \\
\hline $10-$ & & [Idea generation stage] \\
\hline \multirow[t]{4}{*}{11} & & Brainstorming \\
\hline & & Categorize idea importance and degrees of execution \\
\hline & & Writing reflection journals \\
\hline & & $\begin{array}{l}\text { Materials: [Idea generation stage] Introduction video, brainstorming activity sheet, idea analysis ac- } \\
\text { tivity sheet, reflection journal }\end{array}$ \\
\hline $12-$ & & [Prototype stage] \\
\hline \multirow[t]{3}{*}{13} & & Prototype creation \\
\hline & & Writing reflection journals \\
\hline & & Materials:[Prototype stage] introductory video, teaching aids, curriculum templates, reflection journal \\
\hline \multirow[t]{5}{*}{14} & & [Test stage] \\
\hline & & Presentation and demonstration \\
\hline & & Mutual discussion within peer group \\
\hline & & Writing reflection journals \\
\hline & & Materials: [Test stage] introductory video, reflection journal, peer evaluation table \\
\hline
\end{tabular}

In the problem defining stage, the problem is stated through the "5 WHYS (Ohno, 1988)" and "HMW (Basadur, 1995)" strategies. The 5 WHYS are used to reach an understanding of the essential problem situation or cause by asking "Why?" at least five times. HMW is a thinking strategy to imply what solution would be derived in cooperation with the subject who experiences a problem situation by defining the problem in the form of an abbreviation of "How Might We?" In the empathizing stage, preliminary Korean language teachers deeply understand the student's problem situation, and then concretize the problem as an ap- proach to solving it. For example, it can be defined as "How can we teach students who do not like to read?"

In the problem defining stage, the teachers describe the what the problem is with the 5 WHYS and How Might We? techniques. In the idea generation stage, brainstorming is performed to derive ideas for solving problems using sticky notes. Ideas are refined immediately before the prototype by categorizing them in consideration of the importance and degree of execution of the ideas. In this process, convergent and divergent thinking activities can be experienced in depth. 
In the prototype stage, the teachers develop a "Korean language curriculum for a Korean language-friendly classroom and student-customized Korean language classes" based on the results of the empathizing, problem defining, and idea generation stages. Currently, the teachers undergo a free consultation and decision-making process with their fellow prospective teachers. In addition, a "teacher-level Korean language curriculum template" was provided so that the teachers could work on the prototype more easily. For example, strategies such as diagnosing reading ability, visiting a library, conducting a reading workshop, and creating a reading portfolio can be derived.

In the testing stage, prototypes are presented. After the presentation, the preliminary Korean language teachers had time to share their impressions and opinions on the results. An opportunity to hear direct feedback from the teacher who played the role of a student was also provided.

\section{DISCUSSION}

The society of the future demands the cultivation of talented creative convergence individuals, and it is believed that providing education optimized for students based on the national-level curriculum is possible with the curriculum expertise of teachers. This study began from the evaluation that although curriculum literacy is very important for a teacher's curriculum expertise, discussions on it insufficient, and suitable educational programs are not available at the level of teacher education. Since curriculum literacy is the ability to solve complex problems in the educational field by developing a 'teacher-level' curriculum, it shows the possibility of being linked to design thinking. To improve preliminary Korean language teachers' Korean language curriculum literacy this study developed a design thinking-based program.

To that end, the concepts and elements of design thinking and curriculum literacy were first examined in terms of teacher education, and the concepts and elements of Korean language curriculum literacy were reconceptualized. Next, to develop a design thinking-based Korean language curriculum literacy education program, the keynotes necessary for the composition of the program were presented in terms of educational goals, content, methods, and environment, and then the program was developed for accreditation.

However, curriculum literacy and the curriculum expertise of teachers, cannot be nurtured only through one-time training or education. It is not enough to simply know how the curriculum documents are structured and how they have changed. The curriculum literacy of teachers is the professional knowledge of and discerning eye for curriculum components and requires continu- ous research and implementation experience regarding curricula. In other words, after analyzing and understanding national-level curricula in a practical context, teachers should have the experience of developing and implementing an 'optimized' curriculum for students' learning and growth to fit the classroom context.

Through this study, it is expected that preliminary Korean language teachers will be able to systematically develop the curriculum expertise required of teachers by participating in the Korean language curriculum literacy program of teacher training institutes. There have been few discussions on educational programs for preliminary teachers' curriculum literacy, and this study may contribute to the expansion of related discussions.

In addition, design thinking is spreading not only to teacher education, but also to elementary, middle, and high school education. Studies that discussed the possibility of design thinking at the level of teacher education includeKim et al. (2014); Kim et al. (2018); Lee \& Kim (2018) and they are mainly recent studies. The preliminary teachers' educational effectiveness of design thinking was verified in studies conducted by Moon (2018), Seong (2019), Yoon (2019), Hong (2020), and Lee (2020). Design thinking is attracting attention as a future education paradigm, and curriculum literacy, which corresponds to the curriculum expertise of teachers, is an important variable that can affect the quality of education. Therefore, optimal educational models that combine design thinking and curriculum literacy should be proposed and refined.

\section{CONCLUSIONS}

In this paper, the professional practice examined is that of education, specifically, curriculum literacy. i.e., the ability to develop, implement and evaluate curricula. The specific real-world context is developing curriculum literacy in Korean language teachers.

The paper argues that Korean language teachers operate in the real world and therefore need the thinking skills that have a focus on creative solutions, i.e., design thinking skills. However, when viewed from the perspective the children as learners, the problems experienced by children in learning language (both acquisition and literacy) may be derived from cognitive, physical, and emotional issues, particularly in relation to problems with literacy. e.g., dyslexia. The use of the 5WHYS and HMW indicates that some emphasis on the analytic would be appropriate in identifying the root cause of learning problems in language acquisition and literacy.

One of the premises of design thinking is that designers do not start with problems, but an "idea" or "brief" that develops through an iterative and collaborative process and this form of thinking does lead to creative solutions. It therefore does have a place in 
PBL programs where creative, innovative solutions are required such as in teacher education. It is useful as part of a program in curriculum literacy, to cause the teachers to examine their own discipline. In this example, Korean language acquisition and literacy, and develop their own views about the thinking processes involved.

In the future, empirical studies on what effects this program brings about in terms of processes and outcomes compared to other Korean language curriculum literacy programs are necessary. In addition, studies on educational environment elements for more effective implementation of the relevant program and studies on teacher competency as facilitators to lead the program smoothly will also be necessary.

\section{CONFLICT OF INTEREST}

The authors declared no conflict of interest.

\section{ACKNOWLEDGEMENTS}

This paper was supported by funding from the Halla/Newcastle PBL Education and Research Center. The author acknowledges the editorial support provided by Professor Margaret McMillan and Penny Little.

\section{REFERENCES}

Ahn, J. M. (2018). A Case study of curriculum development in Korean teaching using problem-based learning. The Journal of Learner-Centered Curriculum and Instruction, 18(18), 9811002.

Ariav, T. (1988, April). Growth in teachers' curriculum knowledge through the process of curriculum analysis, NY: Annual meeting of the American Educational Research Association.

Basadur, M. (1995). Simplex a flight to creativity, UK: CreativeEducation.

Ben-Peretz, M. (1990). The teacher curriculum encounter: Freeing teachers from the tyranny of texts. Albany: State University of New York Press.

d. School, "Standford d.school Design Thinking", https://dschool. stanford.edu/.

Harvard Business Review. (2008). Https://hber.org/2008/06/ design-thinking/.

Hong, J. M. (2020). The influence of instruction based on design thinking on creative problem-solving and empathy ability of pre-service early childhood teachers. The Journal of Humanities and Social science, 11(1), 1675-1685.
Jeong, G. S. (2012). Study on the teachers`curriculum Literacy. Journal of Curriculum Integration, 6(2), 109-132.

Jeong, H. S. (2002). A study on the aspects that the factors of implementing the curriculum for the department of the Korean language education operate: Centered on the 6th and the 7th middle school curriculum Unpublished doctoral dissertation, Korea University, Korea.

Kim, B. S. (2015). A study on the Korean language curriculum improvement. The Journal of Learner-Centered Curriculum and Instruction, 15(8), 247-265.

Kim, D. I., Choi, S. J., Kim, W. L., Baek, S. H., \& Kim, M. C. (2014). Exploring the concept of 'design' for a new paradigm in education. Asian Journal of Education, 15(4), 29-54.

Kim, H. Y., Bak, J. W., \& Choi. R. M, . (2018). A critical reflection on the concept of education design. Journal of Educational Innovation Research, 28(2), 213-235.

Kim, J. I. (2015). Design thinking education in d.school. Journal of Digital Design, 15(4), 97-108.

Lee, J. G., \& An, Y. H. (2020). Exploring the creativity class experiences of early childhood teachers using d.School of design thinking model. The Journal of Learner-Centered Curriculum and Instruction, 20(2), 203-232.

Lee, J.M. (2020). Case study of 'subject logic and essay' class based on design thinking: focused on critical thinking and creative attitude of pre-service early childhood teacher. The Journal of Learner-Centered Curriculum and Instruction, 20(13), 647673.

Lee, J. Y., \& Kim, H. J. (2020). Mathematics teachers' experience on design thinking based teaching practicum. Communications of Mathematical Education, 34(3), 235-556.

Lee, Y. M., \& Park, H. J. (2020). A Study on the sources of development of integrated curriculum for elementary school teachers. Journal of Curriculum Integration, 14(4), 53-75.

Moon, D. Y. (2018). Applying methods of design thinking in creating problem solving skills of pre-service primary teachers. Journal of Korean Practical Arts Education, 31(2), 21-39.

Nam, C. W., Kwon, J. S., \& Shin, D. M. (2019). The effects of reflection strategies types on pre-service teachers' group cohesiveness and attitude toward cooperative learning in the design thinking learning environments. The Journal of Learner-Centered Curriculum and Instruction, 19(7), 789-812.

Ohno, T. (1988). Toyota production system: beyond large-scale production. Portland, OR: Productivity Press.

Paik, N. J. (2013). Teachers' interpretations of curriculum documents and curriculum potential. The Journal of Curriculum Studies, 31(3), 201-225.

Park, K. Y. (2016). A development of instructional design model 
based on the nature of design thinking. Journal of Educational Technology, 32(4), 837-866.

Park, K. Y. (2018). The effects of instructional design model based on the nature of design thinking on secondary pre-service teacher's instructional design activities. The Journal of Learner-Centered Curriculum and Instruction, 18(3), 191-214.

Park, K. W. (2019). A study on the development of pre-service teachers' design thinking. The Journal of Curriculum Studies, 37(2), 107-130.

Park, Y. K., Kim, M. H., \& Kim, B. S. (2017). A study on the concept of curriculum literacy. CNU Journal of Educational Studies, 38(4), 27-50.

Razzouk, R., \& Shute, V. (2012). What is design thinking and why is it important? Review of Educational Research, 82(3), 330 348.

Rudduck, J. (1987). Can school-based development be other than conservative. In N. Sabar, J. Rudduck., \& W. Reid. (Eds), Partnership and autonomy in school-based curriculum development (pp.80-83): Sheffield: University of Sheffield School of Education.

Seong, G. B. (2019). The effects of problem-based activities with the design thinking process on teaching anxiety, resilience, and creative problem-solving competence of pre-service English teachers. The Journal of Foreign Studies, 47, 41-80.

Seong, J. M. (2019). A study on the development of the design model for the unit of subject. The Journal of Learner-Centered Curriculum and Instruction, 19(19), 269-289.

Simon, H. A. (1969), The sciences of artificial, Cambridge, MA: MIT Press.

Song, M. H. (2020). The literacy components of the curriculums of teachers and current conditions Unpublished doctor dissertation, Chung Nam University, Korea.

Yoon, G. J. (2019). Effects of play instruction class utilizing design thinking on increasing empathy of pre-service early childhood teacher. The Journal of Korea Open Association for Early Childhood Education, 24(3), 1-24. 
